\title{
Preparation and Characterization of Nano Ferrites
}

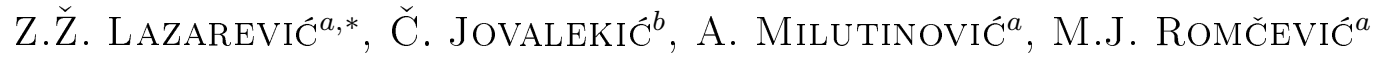 \\ AND N.Ž. ROMČEVIĆ ${ }^{a}$ \\ ${ }^{a}$ Institute of Physics, University of Belgrade, Pregrevica 118, Belgrade, Serbia \\ ${ }^{b}$ The Institute for Multidisciplinary Research, University of Belgrade, Belgrade, Serbia
}

(Received September 20, 2011)

\begin{abstract}
Nickel ferrite $\left(\mathrm{NiFe}_{2} \mathrm{O}_{4}\right)$ and manganese ferrite $\left(\mathrm{MnFe}_{2} \mathrm{O}_{4}\right)$ have been prepared by a soft mechanochemical route from mixture of (1) $\mathrm{Ni}(\mathrm{OH})_{2}$ and $\alpha-\mathrm{Fe}_{2} \mathrm{O}_{3}$ and (2) $\mathrm{Mn}(\mathrm{OH})_{2}$ and $\alpha-\mathrm{Fe}_{2} \mathrm{O}_{3}$ powders in a planetary ball mill. The mixture was activated for varying duration. Soft mechanochemical reaction leading to formation of the $\mathrm{NiFe}_{2} \mathrm{O}_{4}$ and $\mathrm{MnFe}_{2} \mathrm{O}_{4}$ spinel phases were followed by X-ray diffraction, Raman and infrared spectroscopy, scanning and transmission microscopy. The spinel phase formation was first observed after $4 \mathrm{~h}$ of milling (case 1 ) and after $3 \mathrm{~h}$ (case 2) and its formation was completed after $25 \mathrm{~h}$ in both cases. The synthesized $\mathrm{NiFe}_{2} \mathrm{O}_{4}$ and $\mathrm{MnFe}_{2} \mathrm{O}_{4}$ ferrites have a nanocrystalline structure with a crystallite size of about 30 and $40 \mathrm{~nm}$ for cases (1) and (2), respectively. There are five Raman and four IR active modes. In order to understand better the whole process of phase formation, the Mössbauer measurements were done.
\end{abstract}

PACS: 75.20.-g, 81.07.Wx, 81.20.Ev, 74.25.nd

\section{Introduction}

Magnetic nanocrystals and nanosized ferrites have been attracting extensive attention due to their wide applications, such as magnetic memory [1], MRI contrast agents [2], efficient hyperthermia for cancer therapy [3, 4] and catalysts [5], etc. Among these magnetic materials, spinel-type ferrite nanoparticles, $\mathrm{MFe}_{2} \mathrm{O}_{4}(\mathrm{M}=\mathrm{Mn}$, $\mathrm{Co}, \mathrm{Ni}, \mathrm{Zn}, \mathrm{Mg}, \mathrm{Fe}$, etc.), have gained great interest in the past few years because of their good electromagnetic performance and their applications in information storage, medical diagnosis technology, sensor technology, and magnetic warming and cooling technology [6]. The structural formula of spinel-type ferrites can be written as $\left(\mathrm{M}_{1-\lambda}^{2+} \mathrm{Fe}_{\lambda}^{3+}\right)\left[\mathrm{M}_{\lambda}^{2+} \mathrm{Fe}_{2-\lambda}^{3+}\right] \mathrm{O}_{4}$, where parentheses and square brackets denote cation sites of tetrahedral (A) and octahedral (B) coordination, respectively. $\lambda$, which is determined by the preparation process, represents the so-called degree of inversion defined as the fraction of the (A) sites occupied by $\mathrm{Fe}^{3+}$ cations [7].

$\mathrm{NiFe}_{2} \mathrm{O}_{4}$ and $\mathrm{MnFe}_{2} \mathrm{O}_{4}$ ferrites have been synthesized by various methods such as solid-state reaction, co-precipitation, high-temperature self-propagating, microemulsion, solvothermal, mechanosynthesis, hydrothermal, sol-gel and combustion techniques [8-15].

In this paper, we present the formation of spinel ferrite phase through soft mechanochemical treatment [16], starting from different mixtures of powders. The cases were: (1) milling of powders mixture of $\mathrm{Ni}(\mathrm{OH})_{2}+$ $\alpha-\mathrm{Fe}_{2} \mathrm{O}_{3}$ during $4-25 \mathrm{~h}$ and (2) milling of mixture of $\mathrm{Mn}(\mathrm{OH})_{2}+\alpha-\mathrm{Fe}_{2} \mathrm{O}_{3}$ during 3-25 h. The Raman

\footnotetext{
* corresponding author; e-mail: lzorica@yahoo.com
}

and IR spectroscopy in addition to the X-ray diffraction, scanning electron microscopy, transmission electron microscopy and Mössbauer spectroscopy measurements were used to study the samples mechanochemically treated for different milling times.

\section{Experimental}

The following crystalline powders were used as starting materials: (1) nickel(II)-hydroxide $\left(\mathrm{Ni}(\mathrm{OH})_{2}\right.$, Merck $95 \%$ purity $)$ and hematite $\left(\alpha-\mathrm{Fe}_{2} \mathrm{O}_{3}\right.$, Merck $99 \%$ purity $)$ and (2) manganese(II)-hydroxide $\left(\mathrm{Mn}(\mathrm{OH})_{2}\right.$, Merck $95 \%$ purity) and hematite ( $\alpha-\mathrm{Fe}_{2} \mathrm{O}_{3}$, Merck $99 \%$ purity). Soft mechanochemical synthesis was performed in air atmosphere in planetary ball mill (Fritsch Pulverisette 5). All samples, with different starting compositions and milling times, were prepared and milled separately. At the expiration of the selected milling times $(4,10$ and $25 \mathrm{~h}$ for the (1) case and 3,12 and $25 \mathrm{~h}$ for (2) case) the mill was stopped and a small amount of powder was removed from the vial for examination.

Characterization of the obtained samples was carried out by:

- X-ray diffraction (XRD) analysis of powders treated for various periods of milling times by a Philips PW 1050 diffractometer equipped with a PW 1730 generator $(40 \mathrm{kV} \times 20 \mathrm{~mA})$ using $\mathrm{Ni}$ filtered $\mathrm{Cu} K_{\alpha}$ radiation at the room temperature. Measurements were done in $2 \theta$ range of $10-80^{\circ}$ with scanning step width of $0.05^{\circ}$ and 10 s scanning time per step. After XRD measurements, the powder was placed back in a vial to obtain the same grinding conditions (balls to powder weight ratio).

- The Raman measurements of mixture powders were performed using Jobin-Ivon T64000 monochromator. An 
optical microscope with $100 \times$ objective was used to focus the $514 \mathrm{~nm}$ radiation from a Coherent Innova $99 \mathrm{Ar}^{+}$ laser on the sample. The same microscope was used to collect the backscattered radiation. The scattering light dispersed was detected by a charge-coupled device (CCD) detection system. Room temperature Raman spectra are in spectral range from 100 to $800 \mathrm{~cm}^{-1}$. The average power density on the sample was $20 \mathrm{~mW} \mathrm{~mm}^{-2}$.

- The infrared (IR) measurements were carried out with a BOMMEM DA-8 FIR spectrometer. A DTGS pyroelectric detector was used to cover the wave number range from 50 to $700 \mathrm{~cm}^{-1}$.

- The morphology of powders and the size of soft mechano-synthesized ferrite crystallites were examined by scanning electron microscopy (SEM, Model TESCAN Vega TS130MM) and transmission electron microscopy (200 kV TEM, Model JEM-2100 UHR, Jeol Inc., Tokyo, Japan).

- The Mössbauer spectra of powder samples were measured at room temperature (RT) using a source of ${ }^{57} \mathrm{Co}$ in $\mathrm{Rh}(1.85 \mathrm{GBq})$. The experiments were performed in standard transmission geometry with constant acceleration calibrated by the laser spectrum. The data were analyzed by The WinNormos Site program [17]. Sample thickness correction was carried out by transmission integral.

\section{Results and discussion}

Soft mechanochemical synthesis and mechanical milling of (1) $\mathrm{Ni}(\mathrm{OH})_{2}+\mathrm{Fe}_{2} \mathrm{O}_{3} \rightarrow \mathrm{NiFe}_{2} \mathrm{O}_{4}+\mathrm{H}_{2} \mathrm{O}$ and (2) $\mathrm{Mn}(\mathrm{OH})_{2}+\mathrm{Fe}_{2} \mathrm{O}_{3} \rightarrow \mathrm{MnFe}_{2} \mathrm{O}_{4}+\mathrm{H}_{2} \mathrm{O}$ was also carried out under air atmosphere. Figure 1a shows the $\mathrm{X}$-ray diffraction patterns of stoichiometric mixtures of powdered reactants $\mathrm{Ni}(\mathrm{OH})_{2}$ and $\alpha-\mathrm{Fe}_{2} \mathrm{O}_{3}$ in a ball mill for different times $(4,10$, and $25 \mathrm{~h})$. The XRD pattern of the starting powder is characterized by diffraction peaks corresponding to crystalline $\mathrm{Ni}(\mathrm{OH})_{2}$ (JCPDS card 74-2075), NiO (JCPDS card 89-5881), NiOOH (JCPDS card 27-0956), $\alpha-\mathrm{Fe}_{2} \mathrm{O}_{3}$ (JCPDS card 89-8104), $\mathrm{FeO}(\mathrm{OH})$ (JCPDS card 89-6096) and $\mathrm{NiFe}_{2} \mathrm{O}_{4}$ (JCPDS card 89-4927). It can be noticed that the major peaks for the hematite phase at $2 \theta=35.6^{\circ}$ and $33.15^{\circ}$ were continuously reduced by increasing the milling time (Fig. 1a). One can observe slightly wider $\alpha-\mathrm{Fe}_{2} \mathrm{O}_{3}$ peaks of lower intensity and almost disappearing $\mathrm{Ni}(\mathrm{OH})_{2}$ peaks. It is important to note that during the milling of powder mixtures between 4 and $10 \mathrm{~h}$ occurs a phase $\mathrm{FeO}(\mathrm{OH})$ (JCPDS card 89-6096) and NiO (JCPDS card 89-5881), too. The main reason for this phenomenon is because powder $\mathrm{Fe}_{2} \mathrm{O}_{3}$ in an atmosphere wet and heated by intensive milling reacts with water and $\mathrm{Ni}(\mathrm{OH})_{2}$ quickly decomposes through $\mathrm{Ni}(\mathrm{OH})_{2} \rightarrow \mathrm{NiO}+\mathrm{H}_{2} \mathrm{O}$, so that after $4 \mathrm{~h}$ of milling (Fig. 1a) there are a negligible number of peaks corresponding to the starting compound $\mathrm{Ni}(\mathrm{OH})_{2}$. Further milling up to $25 \mathrm{~h}$ leads to full synthesis of new phase. All the diffraction peaks $\left(18.4^{\circ}, 30.1^{\circ}\right.$, $35.6^{\circ}, 37.3^{\circ}, 43.4^{\circ}, 57.4^{\circ}$ and $62.8^{\circ}$ ) of the pattern for
$25 \mathrm{~h}$ of milling time are well indexed as cubic spinel phase with the fcc structure (fcc - face cubic centered). The diffractogram shows different reflection planes indexed as $(k h l)$ (111), (220), (311), (222), (400), (511) and (440), which indicates the spinel cubic structure of $\mathrm{NiFe}_{2} \mathrm{O}_{4}$ [18].

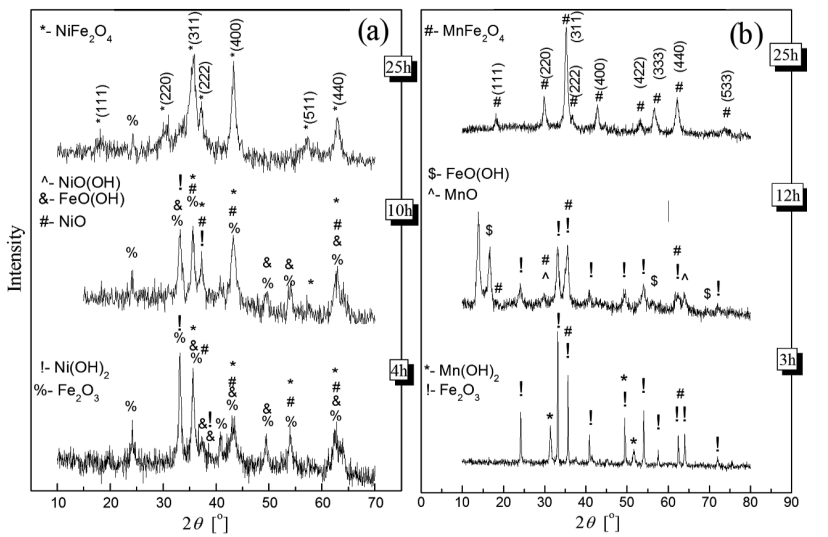

Fig. 1. X-ray diffraction pattern of the mixture of (a) $\mathrm{Ni}(\mathrm{OH})_{2}$ and $\alpha-\mathrm{Fe}_{2} \mathrm{O}_{3}$ and (b) $\mathrm{Mn}(\mathrm{OH})_{2}$ and $\alpha$ $\mathrm{Fe}_{2} \mathrm{O}_{3}$ powders after various milling times.

Figure $1 \mathrm{~b}$ shows the $\mathrm{X}$-ray diffraction patterns of mixture of $\mathrm{Mn}(\mathrm{OH})_{2}$ and $\alpha-\mathrm{Fe}_{2} \mathrm{O}_{3}$ powders mechanochemically activated for different milling times $(3,12$, and $25 \mathrm{~h}$ ). The XRD pattern of the starting powder is characterized by sharp diffraction peaks corresponding to crystalline $\mathrm{Mn}(\mathrm{OH})_{2}$ (JCPDS card 73-1133) and $\alpha-\mathrm{Fe}_{2} \mathrm{O}_{3}$ (JCPDS card 89-8103) [19]. With increasing milling time, the diffraction peaks corresponding to the simple oxide and hydroxide gradually disappear. All the characteristic peaks of $\mathrm{Mn}(\mathrm{OH})_{2}$ and $\alpha-\mathrm{Fe}_{2} \mathrm{O}_{3}$ are well pronouced in the spectrum (Fig. 1b). During mechanochemical treatment $(3 \mathrm{~h})$ only sharp peaks from the well-crystallized $\mathrm{Mn}(\mathrm{OH})_{2}$ and $\alpha-\mathrm{Fe}_{2} \mathrm{O}_{3}$ are present in the XRD pattern. The new phases of $\mathrm{FeO}(\mathrm{OH})$ (JCPDS card 89-6096) and MnO (JCPDS card 75-1090) occur during the milling of powder mixtures between 3 and $12 \mathrm{~h}$. It is known that the milling process leads to overheating of the vessel, and at temperatures higher than $100^{\circ} \mathrm{C}$ - to the evolution of water vapor.

Opening the container leads to partial evaporation of water. It might be noted that the hydroxides transform into oxides. At the same time, there can be observed the peaks characteristic of the hydroxide and oxide (Fig. 1b). This may be a consequence of opening of the milling vessel. The reason is almost the same for the samples obtained from the mixture of powders for $12 \mathrm{~h}$ of milling time. This means that there is no further milling up to $12 \mathrm{~h}$ which leads to full synthesis of new phase. The appearance of the new peak at $2 \theta=18.09^{\circ}, 29.89^{\circ}$, $35.37^{\circ}, 42.85^{\circ}, 53.11^{\circ}, 56.76^{\circ}, 62.13^{\circ}$ and $73.74^{\circ}$, clearly indicates the formation of the new phase of $\mathrm{MnFe}_{2} \mathrm{O}_{4}$ (JCPDS card 74-2403) (Fig. 1b). The peaks are well indexed to the crystal plane of spinel ferrite $(k h l)(111)$, 
(220), (311), (400), (333), (440) and (533), respectively. This confirms that the mechanochemical synthesis of $\mathrm{MnFe}_{2} \mathrm{O}_{4}$ is feasible and complete for $25 \mathrm{~h}$ milling time.

The full width at half maximum of the XRD peaks was used to calculate the crystallite size $D$ of $\mathrm{NiFe}_{2} \mathrm{O}_{4}$ and $\mathrm{MnFe}_{2} \mathrm{O}_{4}$ powders using Scherrer's relation [20]:

$$
D=0.9 \lambda /(\beta \cos \theta),
$$

where $D$ is the crystallite grain size, $\lambda=1.5406 \AA$ is the wavelength of the $\mathrm{Cu} K_{\alpha}, \beta$ is the broadening of the diffraction line measured at half maximum intensity (radians). The resulting value of the crystallite size, obtained from the (311) strongest reflections, are $30 \mathrm{~nm}$ for $\mathrm{NiFe}_{2} \mathrm{O}_{4}$ and $40 \mathrm{~nm}$ for $\mathrm{MnFe}_{2} \mathrm{O}_{4}$, respectively.

XRD is the most useful analysis method for determining the crystalline structure of materials. But, the XRD of nanocrystalline materials does not provide sufficient intensity of diffraction peaks necessary to determine the complete crystallographic information. Additional methods, like the Raman and IR analysis, are required to achieve the structure analysis of nanocrystalline materials in order to distinguish $\mathrm{MFe}_{2} \mathrm{O}_{4}(\mathrm{M}=\mathrm{Mn}, \mathrm{Co}, \mathrm{Ni}$, $\mathrm{Cu}, \mathrm{Zn}, \mathrm{Mg}, \mathrm{Cd}$, etc.) from $\mathrm{Fe}_{3} \mathrm{O}_{4}$ or $\gamma-\mathrm{Fe}_{2} \mathrm{O}_{3}$ (possible impurity phases) with similar structure elements and therefore similar XRD patterns.

The crystal structure of $\mathrm{M}^{2+} \mathrm{Fe}_{2}^{3+} \mathrm{O}_{4}^{2-}\left(\mathrm{M}^{2+}=\mathrm{Mn}\right.$ or $\mathrm{Ni}$ ) is spinel (space group $F d 3 m$ ) in which the lattice of $\mathrm{O}^{2-}$ ions forms tetrahedral (A-sites) and octahedral (B-sites) local symmetry. In normal spinel structure, divalent $\mathrm{M}^{2+}$ ions only occupy $\mathrm{A}$ sites, and trivalent $\mathrm{Fe}^{3+}$ ions occupy B sites. In inverse spinel structure, divalent ions occupy half of B sites, and trivalent ions occupy the rest of B sites and all A sites. Group theory predicts 5 Raman active modes in spinel structure: $A_{1 \mathrm{~g}}+E_{\mathrm{g}}+3 F_{2 \mathrm{~g}}$ and four $F_{1 \mathrm{u}}$ infrared active.

$\mathrm{NiFe}_{2} \mathrm{O}_{4}$ has (mostly) inverse spinel structure. All five Raman peaks in $\mathrm{NiFe}_{2} \mathrm{O}_{4}$ are asymmetric, with shoulder on the low energy side. Each peak can be presented like a doublet. Additional peaks are related to the presence of non-equivalent atoms at the B-sites (but with structural ordering over B-sites). At a microscopic level the structure of $\mathrm{NiFe}_{2} \mathrm{O}_{4}$ can be considered as a mixture of two sublattices with $\mathrm{Fe}^{3+}$ and $\mathrm{Ni}^{2+}$. In nanocrystalline samples asymmetry is partly due to confinement and size-distribution of nanoparticles. It is confirmed that structure of $\mathrm{NiFe}_{2} \mathrm{O}_{4}$ depends on the synthesizing conditions [21]. $\mathrm{NiFe}_{2} \mathrm{O}_{4}$ may be characterized as a mixture of normal and inverse spinel ferrite. With the increase of the calcination temperature or milling time the structure changes from pure normal spinel structure to mixed spinel structure and single broad bands in the Raman spectra became asymmetric, with double peak like structure.

The Raman spectra of $\mathrm{MnFe}_{2} \mathrm{O}_{4}$ nanocrystalline samples, obtained by mechanochemical method at low temperature, have hardly visible doublet structure and it could be concluded that spinel structure of these samples is mostly normal.

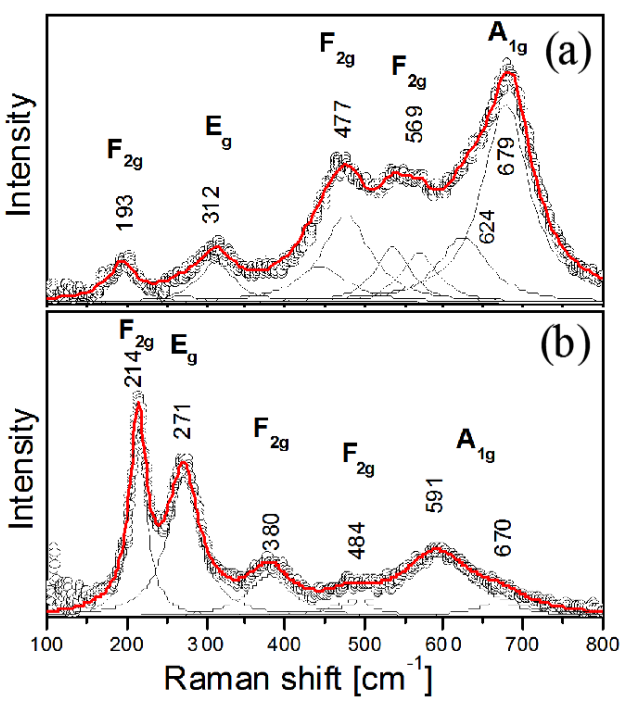

Fig. 2. Raman spectra at room temperature of the mixture of: (a) $\mathrm{Ni}(\mathrm{OH})_{2}$ and $\alpha-\mathrm{Fe}_{2} \mathrm{O}_{3}$ and (b) $\mathrm{Mn}(\mathrm{OH})_{2}$ and $\alpha-\mathrm{Fe}_{2} \mathrm{O}_{3}$ powders after $25 \mathrm{~h}$ milling time.

The Raman spectra of samples, obtained by mixing of (1) $\mathrm{Ni}(\mathrm{OH})_{2}$ and $\alpha-\mathrm{Fe}_{2} \mathrm{O}_{3}$ and (2) $\mathrm{Mn}(\mathrm{OH})_{2}$ and $\alpha-\mathrm{Fe}_{2} \mathrm{O}_{3}$ for $25 \mathrm{~h}$ are analysed by deconvolution (Fig. 2) and modes are assigned, as usual. In the cubic ferrites, the modes at above $600 \mathrm{~cm}^{-1}$ mostly correspond to the motion of oxygen in tetrahedral $\mathrm{AO}_{4}$ groups, so the mode at $679 \mathrm{~cm}^{-1}$ for $\mathrm{NiFe}_{2} \mathrm{O}_{4}$ and dublet modes at $591-670 \mathrm{~cm}^{-1}$ for $\mathrm{MnFe}_{2} \mathrm{O}_{4}$ can be reasonably considered as $A_{\mathrm{g}}$ symmetry. The other low frequency modes represent the characteristics of the octahedral sites $\left(\mathrm{BO}_{6}\right)$. The mode, observed at around $679 \mathrm{~cm}^{-1}$ for $\mathrm{NiFe}_{2} \mathrm{O}_{4}$ and $591-670 \mathrm{~cm}^{-1}$ for $\mathrm{MnFe}_{2} \mathrm{O}_{4}$ can be assigned to tetrahedral $\mathrm{Ni}^{2+}$ and $\mathrm{Mn}^{2+}$ stretching, and band observed at $477 \mathrm{~cm}^{-1}$ and $484 \mathrm{~cm}^{-1}$ involves the $\mathrm{Fe}^{3+}$ vibration at the octahedral site in both cases. The five first-order Raman modes at about 193, 312, 477, 599 and $679 \mathrm{~cm}^{-1}$ (Fig. 2a) and 214, 271, 380,484 and $591-670 \mathrm{~cm}^{-1}$ exhibit the broad characteristics. The obtained three modes at about 193, 477 and $599 \mathrm{~cm}^{-1}$ for $\mathrm{NiFe}_{2} \mathrm{O}_{4}$ and 214, 380 and $484 \mathrm{~cm}^{-1}$ for $\mathrm{MnFe}_{2} \mathrm{O}_{4}$ belong to the symmetry type $F_{2 \mathrm{~g}}$. Also, it can see that the modes 312 and $271 \mathrm{~cm}^{-1}$ belong to same symmetry $E_{\mathrm{g}}$ for $\mathrm{NiFe}_{2} \mathrm{O}_{4}$ and $\mathrm{MnFe}_{2} \mathrm{O}_{4}$, respectively.

For further characterization of the synthesized $\mathrm{NiFe}_{2} \mathrm{O}_{4}$ and $\mathrm{MnFe}_{2} \mathrm{O}_{4}$ ferrites, IR spectra were recorded in the range of $50-700 \mathrm{~cm}^{-1}$ (Fig. 3). The most exaggerated features in spectra, $F_{1 \mathrm{u}}(3)$ and $F_{1 \mathrm{u}}(4)$, correspond to the vibrations of positive ions in $\mathrm{NiFe}_{2} \mathrm{O}_{4}$ and $\mathrm{MnFe}_{2} \mathrm{O}_{4}$ in octahedral and tetrahedral sites, respectively. It is known that the higher band at $\approx 700 \mathrm{~cm}^{-1}$ corresponds to the intrinsic vibrations of tetrahedral site and the lower band at $\approx 400 \mathrm{~cm}^{-1}$ is attributed to the vibrations of octahedral site. The different values of the energy position for these modes are due to different values of metal ion- $\mathrm{O}^{2-}$ distances for octahedral and tetrahedral sites. In reflectivity spectra of $\mathrm{NiFe}_{2} \mathrm{O}_{4}$ TO-LO splitting of $F_{1 \mathrm{u}}(4)$ IR mode is visible. 


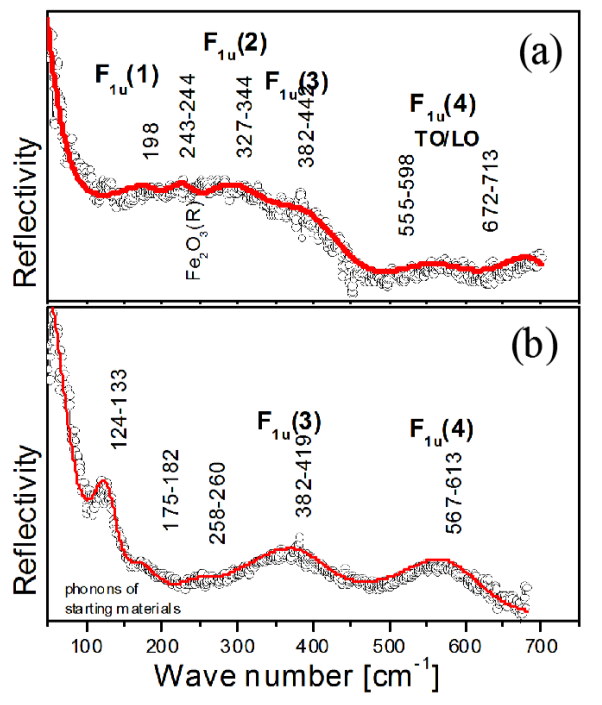

Fig. 3. IR spectra at room temperature of the mixture of: (a) $\mathrm{Ni}(\mathrm{OH})_{2}$ and $\alpha-\mathrm{Fe}_{2} \mathrm{O}_{3}$ and (b) $\mathrm{Mn}(\mathrm{OH})_{2}$ and $\alpha-\mathrm{Fe}_{2} \mathrm{O}_{3}$ powders after $25 \mathrm{~h}$ milling time.

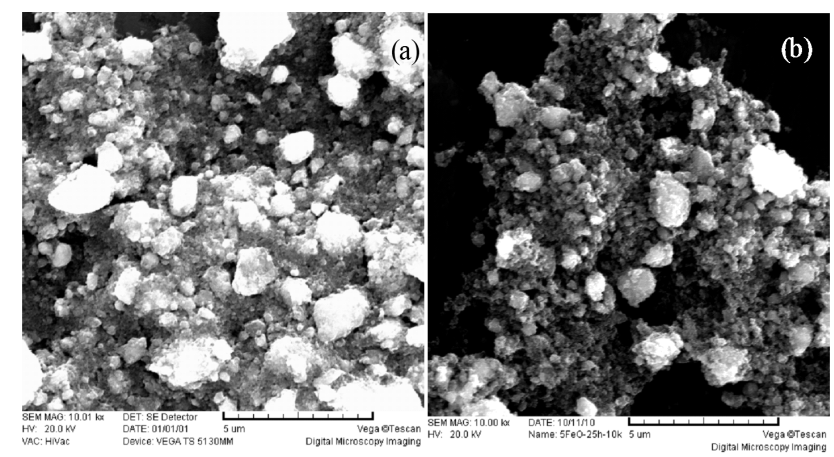

Fig. 4. SEM images of nanoscale of mechanosynthesized (a) $\mathrm{NiFe}_{2} \mathrm{O}_{4}$ and (b) $\mathrm{MnFe}_{2} \mathrm{O}_{4}$ powders after $25 \mathrm{~h}$ of milling time.

Figure 4 shows the SEM micrographs for the sample obtained from the mixture of (1) $\mathrm{Ni}(\mathrm{OH})_{2}$ and $\mathrm{Fe}_{2} \mathrm{O}_{3}$ and (2) $\mathrm{Mn}(\mathrm{OH})_{2}$ and $\mathrm{Fe}_{2} \mathrm{O}_{3}$ powders by the soft mechanochemical synthesis after $25 \mathrm{~h}$ milling time, respectively. As result of mechanochemical reaction, the powders become much finer and uniform in shape. While the starting powder mixture consisted predominantly of individual particles, the sample of mechanosynthesized manganese ferrite consists of aggregates of fine particles. The shape of the majority of the crystallities appeared to be spherical. The surface morphology of the sample as seen from the SEM consists of the grains, with relatively homogeneous grain distribution, with an average grain size varying from 1 to $3 \mu \mathrm{m}$.

The representative TEM image of the manganese ferrite is shown in Fig. 5. It indicates that the manganese ferrite particles obtained by this method are uniform in both morphology and crystallite size, but having agglom-

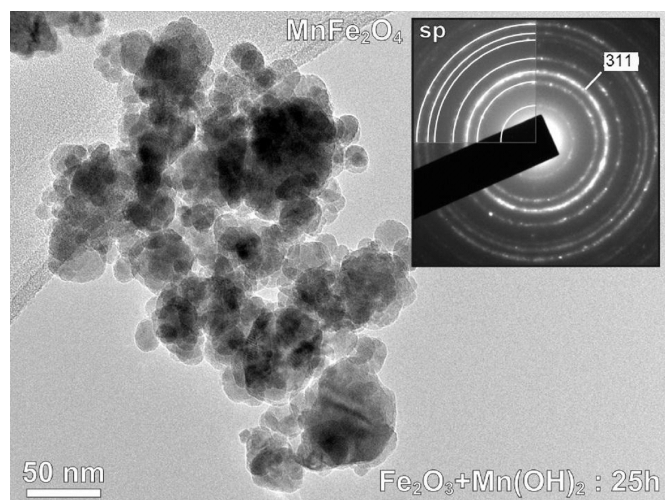

Fig. 5. TEM image with corresponding EDP of $\mathrm{Mn}(\mathrm{OH})_{2}$ and $\alpha-\mathrm{Fe}_{2} \mathrm{O}_{3}$ after milling for $25 \mathrm{~h}$. Spinel-type reflections dominate the diffraction pattern (inset).

eration to some extent, due to the relative higher interaction between magnetic particles. The manganese ferrite sample obtained after $25 \mathrm{~h}$ of milling exhibits the shape with crystallite sizes in the range of $10-50 \mathrm{~nm}$. In addition, the electron diffraction pattern corresponding to the sample obtained for $25 \mathrm{~h}$ of milling time shown in Fig. 5 can be well indexed to (111), (220), (311), (400), (333), (440) and (533) of cubic spinel structure, which is consistent with the results of XRD.

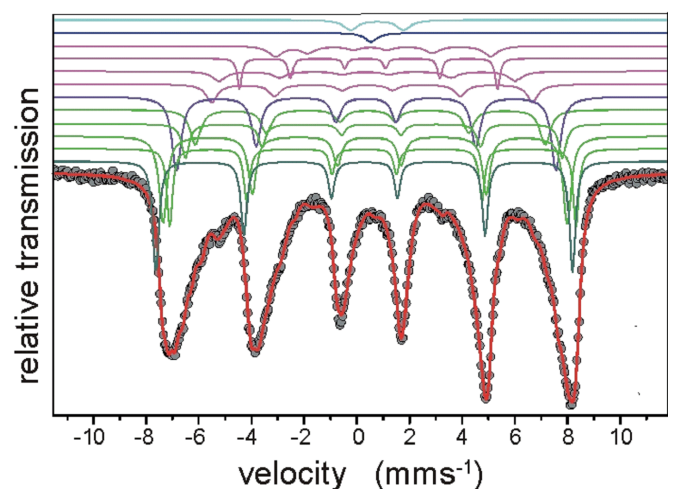

Fig. 6. Mössbauer spectra at room temperature of the mixture of $\mathrm{Mn}(\mathrm{OH})_{2}$ and $\alpha-\mathrm{Fe}_{2} \mathrm{O}_{3}$ powders after $25 \mathrm{~h}$ milling time.

Figure 6 shows two Mössbauer spectra for samples obtained at room temperature from the mixture of: (1) $\mathrm{Ni}(\mathrm{OH})_{2}$ and $\alpha-\mathrm{Fe}_{2} \mathrm{O}_{3}$ and $(2) \mathrm{Mn}(\mathrm{OH})_{2}$ and $\alpha-\mathrm{Fe}_{2} \mathrm{O}_{3}$ powders after $25 \mathrm{~h}$ milling time. The Mössbauer spectra for both samples consist of the twelve subspectra. They are divided into three groups, depending on the particles size. A large nanoparticle requires five subspectra to describe cation distribution at the mixed spinel $\left(\mathrm{Mn}_{x} \mathrm{Fe}_{1-x}\right)^{\mathrm{T}}\left(\mathrm{Mn}_{1-x} \mathrm{Fe}_{1+x}\right)^{\mathrm{M}} \mathrm{O}_{4}$. The first sextet is assigned to ferric ion at tetrahedral site $(\mathrm{T})$ with the cubic point symmetry group $T d$. It is confirmed with zero quadrupole splitting. Cations at this site feel the 
strongest antiferromagnetic hyperfine interaction as result of the superexchange interaction via oxygen ions. The ferric ions positioned at octahedral coordination site (M) show four sextets due to different local environment. The ferric cations at $(\mathrm{M})$ site are very sensitive to the distribution of cations at $(\mathrm{T})$ site [17]. Therefore, the belonged sextets have broadened line widths. The octahedral site has the trigonal point symmetry $D 3 d$ group, and one expects certain electric field gradient (EFG). The strength of hyperfine induction depends on the distance between the magnetic ions and angle of $\mathrm{Fe}-\mathrm{O}-\mathrm{Fe}$ bonds Also, the strength decreases as the volume of particles decreases.

The superparamagnetic relaxation effect occurs at very small nanoparticles and we cannot observe a sextet any more, as consequence. It is found that the one doublet and the singlet are presented, originating from octahedral and tetrahedral coordination, respectively. The cation site preference is affected when the size of particles is small, too. We found out in the first sample obtained from the mixture of $\mathrm{Mn}(\mathrm{OH})_{2}$ and $\alpha-\mathrm{Fe}_{2} \mathrm{O}_{3}$ powders after $25 \mathrm{~h}$ milling time that amount of $\mathrm{Mn}^{2+}$ at tetrahedral site decreases from $76 \%$ to $51 \%$, as size of particles decreased. The analysis of the Mössbauer spectra of the investigated nanocrystalline ferrites obtained by mechanochemical treatment quantitatively confirm that $\mathrm{NiFe}_{2} \mathrm{O}_{4}$ has an inverse spinel structure and $\mathrm{MnFe}_{2} \mathrm{O}_{4}$ has mixed, mostly normal spinel structure.

\section{Conclusions}

In this paper, we show that it is possible to obtain $\mathrm{NiFe}_{2} \mathrm{O}_{4}$ and $\mathrm{MnFe}_{2} \mathrm{O}_{4}$ ferrites by soft mechanochemical synthesis starting from the mixture of (1) $\mathrm{Ni}(\mathrm{OH})_{2}$ and $\alpha-\mathrm{Fe}_{2} \mathrm{O}_{3}$ and (2) $\mathrm{Mn}(\mathrm{OH})_{2}$ and $\alpha-\mathrm{Fe}_{2} \mathrm{O}_{3}$ powders. It has been shown that mechanochemical treatment of mixtures with starting materials leads to the amorphization of the starting powders, forming the phase of $\mathrm{Ni}(\mathrm{OH})_{2}, \mathrm{NiO}$, $\mathrm{NiO}(\mathrm{OH}), \mathrm{FeO}(\mathrm{OH})$ and $\mathrm{Fe}_{2} \mathrm{O}_{3}$ after $4 \mathrm{~h}$ and $10 \mathrm{~h}$ of milling, and only $\mathrm{NiFe}_{2} \mathrm{O}_{4}$ phase after $25 \mathrm{~h}$, (case 1 ). On the other hand, observing case (2), $\mathrm{Mn}(\mathrm{OH})_{2}$ and $\mathrm{Fe}_{2} \mathrm{O}_{3}$ phases occur after $3 \mathrm{~h}$ of milling, $\mathrm{Fe}_{2} \mathrm{O}_{3}, \mathrm{MnO}$ and $\mathrm{FeO}(\mathrm{OH})$ phases after $12 \mathrm{~h}$ and finally after $25 \mathrm{~h}$ only $\mathrm{MnFe}_{2} \mathrm{O}_{4}$ phase. On the basis of the Raman research there are observed five first-order Raman active modes. The intensity of the Raman and IR modes in the formation of $\mathrm{NiFe}_{2} \mathrm{O}_{4}$ and $\mathrm{MnFe}_{2} \mathrm{O}_{4}$ ferrite phases is rather low, as it is expected for nanocrystalline samples. The surface morphology of the samples consists of the grains with relatively homogeneous distribution as seen from SEM. Crystallite size estimated from Scherrer's formula is consistent with the results of TEM. The Mössbauer spectra show the one doublet and the singlet, originating from octahedral and tetrahedral coordination, respectively. The cation site preference is affected when the size of particles are small, too. We found out that amount of $\mathrm{Mn}^{2+}$ at tetrahedral site decreases as size of particles decreased.

\section{Acknowledgments}

This research was financially supported by the Serbian Ministry of Education and Science through projects No. III45003 and 45015 .

\section{References}

[1] S.S.P. Parkin, M. Hayashi, L. Thomas, Science 320 , 190 (2008).

[2] S. Mornet, S. Vasseur, F. Grasset, P. Veverka, G. Goglio, A. Demourgues, J. Portier, E. Pollert, E. Dugust, Prog. Solid State Chem. 34, 237 (2006).

[3] D.L. Zhao, X.W. Zeng, Q.S. Xia, J.T. Tang, J. Alloys Comp. 469, 215 (2009).

[4] J.P. Fortin, F. Gazeau, C. Wilhelm, Eur. Biophys. J. 37, 223 (2008).

[5] C.S. Gill, W. Long, C.W. Jones, Catal. Lett. 131, 425 (2009).

[6] V. Šepelák, I. Bergmann, A. Feldhoff, P. Heitjans, F. Krumeich, D. Menzel, F.J. Litterst, S.J. Campbell, K.D. Becker, J. Phys. Chem. C 111, 5026 (2007).

[7] L. Wang, J. Ren, Y. Wang, X. Liu, Y. Wang, J. Alloys Comp. 490, 656 (2010).

[8] A. Baykal, N. Kasapoğlu, Y. Köseoğlu, M.S. Toprak, H. Bayrakdar, J. Alloys Comp. 464, 514 (2008).

[9] P. Osmokrovic, C. Jovalekic, D. Manojlovic, M.B. Pavlovic, J. Opto. Adv. Mater. 8, 312 (2006).

[10] V. Šepelák, M. Menzel, I. Bergman, M. Wiebcke, F. Krumeich, K.D. Becker, J. Magn. Magn. Mater. 272, 1618 (2004).

[11] J. Azadmanjiri, S.A. Seyyed Ebrahimi, H.K. Salehani, Ceram. Int. 33, 1623 (2007).

[12] R.V. Mangalaraja, S. Anathakmar, P. Monohar, F.D. Gnanam, M. Awana, J. Mater. Sci. Eng. A 367, 301 (2004).

[13] M.A. Ahmed, E.H. El-Khawas, F.A. Radwan, J. Mater. Sci. 36, 5031 (2001).

[14] M. Muroi, R. Street, P.G. McCormick, J. Amighian, Phys. Rev. B 63, 184414 (2001).

[15] F. Padella, C. Alvani, A. La Barbera, G. Ennas, R. Liberatore, F. Varsano, Mater. Chem. Phys. 90, 172 (2005).

[16] E. Avvakumov, M. Senna, N. Kosova, Soft Mechanochemical Synthesis: A Basis for New Chemical Technologies, Kluwer Academic Publishers, Boston 2001.

[17] M. Siddique, N.M. Butt, Physica B 405, 4211 (2010).

[18] A.M. El Sayed, Ceram. Int. 28, 363 (2002).

[19] Joint Committee on Powder Diffraction Standards (JCPDS) Powder Diffraction File (PDF): International Centre for Diffraction Data: Newton Square, PA 2003.

[20] Scherrer and Warren equations (B.E. Warren, X-ray Diffraction, Addison Wesley, Reading MA 1969).

[21] A. Ahlawat, V.G. Sathe, V.R. Reddy, A. Gupta, J. Magn. Magn. Mater. 323, 2049 (2011). 